\title{
Comparative analysis of the complete sequence of the plastid genome of Parthenium argentatum and identification of DNA barcodes to differentiate Parthenium species and lines Shashi Kumar ${ }^{1,2}$, Frederick M Hahn ${ }^{1}$, Colleen M McMahan'1, Katrina Cornish ${ }^{2}$ and Maureen C Whalen*1
}

Address: ${ }^{1}$ Crop Improvement and Utilization Research Unit, Western Regional Research Center, ARS, USDA, 800 Buchanan Street, Albany CA 94710, USA and 2Yulex Corporation, 37860 W Smith-Enke Road, Maricopa, AZ 85238-3010, USA

Email: Shashi Kumar - shashi.kumar@ars.usda.gov; Frederick M Hahn - doktorphred@earthlink.net; Colleen M McMahan - colleen.mcmahan@ars.usda.gov; Katrina Cornish - kcornish@yulex.com; Maureen C Whalen* - maureen.whalen@ars.usda.gov

* Corresponding author

Published: 17 November 2009

BMC Plant Biology 2009, 9:131 doi:10.1 |86/|47|-2229-9-131
Received: 26 January 2009

Accepted: 17 November 2009

This article is available from: http://www.biomedcentral.com/|47|-2229/9/|3|

(C) 2009 Kumar et al; licensee BioMed Central Ltd.

This is an Open Access article distributed under the terms of the Creative Commons Attribution License (http://creativecommons.org/licenses/by/2.0), which permits unrestricted use, distribution, and reproduction in any medium, provided the original work is properly cited.

\begin{abstract}
Background: Parthenium argentatum (guayule) is an industrial crop that produces latex, which was recently commercialized as a source of latex rubber safe for people with Type I latex allergy. The complete plastid genome of $P$. argentatum was sequenced. The sequence provides important information useful for genetic engineering strategies. Comparison to the sequences of plastid genomes from three other members of the Asteraceae, Lactuca sativa, Guitozia abyssinica and Helianthus annuus revealed details of the evolution of the four genomes. Chloroplast-specific DNA barcodes were developed for identification of Parthenium species and lines.

Results: The complete plastid genome of $P$. argentatum is 152,803 bp. Based on the overall comparison of individual protein coding genes with those in $L$. sativa, $G$. abyssinica and $H$. annuus, we demonstrate that the $P$. argentatum chloroplast genome sequence is most closely related to that of $H$. annuus. Similar to chloroplast genomes in G. abyssinica, L. sativa and H. annuus, the plastid genome of $P$. argentatum has a large $23 \mathrm{~kb}$ inversion with a smaller $3.4 \mathrm{~kb}$ inversion, within the large inversion. Using the matK and psbA-trnH spacer chloroplast DNA barcodes, three of the four Parthenium species tested, $P$. tomentosum, P. hysterophorus and P. schottii, can be differentiated from $P$. argentatum. In addition, we identified lines within $P$. argentatum.

Conclusion: The genome sequence of the $P$. argentatum chloroplast will enrich the sequence resources of plastid genomes in commercial crops. The availability of the complete plastid genome sequence may facilitate transformation efficiency by using the precise sequence of endogenous flanking sequences and regulatory elements in chloroplast transformation vectors. The DNA barcoding study forms the foundation for genetic identification of commercially significant lines of $P$. argentatum that are important for producing latex.
\end{abstract}




\section{Background}

Parthenium argentatum Gray, commonly known as guayule, is a shrub in the Asteraceae that is native to the southwestern United States and northern Mexico. Parthenium argentatum produces high quality rubber in bark tissue, which is under development for biomedical uses. The U.S. Food and Drug Administration recently approved the first medical device made from $P$. argentatum natural rubber. Products made from $P$. argentatum latex are designed for people who have Type I latex allergies, induced by natural rubber proteins from Hevea brasiliensis. In addition to biomedical products, natural rubber is essential and irreplaceable in many industrial and consumer applications, and the price is rising under heavy demand, making natural rubber increasingly more precious. As an industrial crop that grows in temperate climates, $P$. argentatum represents a viable alternative source of high quality natural rubber.

One strategy for improving crops, such as the rubber-producing $P$. argentatum, is through chloroplast engineering [1-3]. Transformation of chloroplasts allows high-level production of foreign proteins because of the high number of chloroplasts per plant cell. As homologous recombination is the means by which foreign DNA is incorporated into the chloroplast genome, transformation is precise and predictable. Moreover, it has been shown that up to four genes can be inserted at once [4], enhancing the efficiency of metabolic engineering. From production of edible vaccines to bioplastics, transplastomic plants have been shown to provide a useful route to manipulate crops for industrial purposes [5].

Importantly from the point of view of minimizing environmental impact, expressing foreign proteins in the chloroplast results in transgene containment [6,7]. It is thought that in the vast majority of plant species, chloroplasts are not transmitted by pollen, and so in these species, chloroplastidic transgenes would not be spread in that manner. Although, it is becoming clear that each case must be thoroughly verified $[8,9]$. In the case of $P$. argentatum, transgene containment is important because it is currently cultivated as an industrial crop in its native region in the southwestern United States.

Construction of vectors for chloroplast transformation requires some knowledge of the chloroplast genome sequence to identify insertion sites. To date, just short of one hundred plastid genomes from angiosperms have been completely sequenced. The sequences are highly conserved [10]. Interestingly however, the order of genes in some groups, including the Asteraceae, Fabaceae and Poaceae, may be reversed by large inversions [11-13]. In the Asteraceae, the family of interest in this study, there is a second small inversion ( $\sim 3 \mathrm{~kb})$ nested within the larger inversion ( $23 \mathrm{~kb})$ [14]. The two inversions are always found together, implying that they occurred close in evolutionary time.

Chloroplast sequences are useful for identification of species, using a particular sequence as a DNA tag or barcode [15]. An ideal DNA barcode for general purposes would 1) have enough diversity to allow discrimination among species, but not so much that would prevent grouping of members of a species, 2) work in wide variety of taxa, and 3 ) provide the basis for reliable amplifications and sequences [16]. In plants, unlike in animals, the mitochondrial genome evolves too slowly to provide useful DNA barcode sequences. Although also possessing a relatively slow rate of evolution, several chloroplast sequences have been identified as fulfilling the criteria listed above [17-19]. Depending on the desired level of discrimination, the consensus conclusion appears to be that the low mutation rate in the chloroplast genome may require more than one barcode locus to be probed [18,20,21].

At present, classical breeding is being used to improve $P$. argentatum as a commercial source of natural rubber. Breeding efforts would be enhanced by informative chloroplast DNA barcodes. Because a very small amount of tissue is required for barcode analysis, purity of breeding lines can be determined at an early stage of seedling growth. In addition, barcodes would allow breeders and seed producers to discover seed lot contamination before advancing breeding lines for latex production. Having the ability to removing contaminating lines, especially when they represent lower rubber lines, would improve the efficacy of breeding efforts.

The focus of our research program is improvement of $P$. argentatum to enhance its commercial viability. We have chosen two approaches, biotechnology through chloroplast metabolic engineering and marker-assisted breeding. The $P$. argentatum chloroplast genome sequence that we report herein, supports our efforts in both approaches. In this article, we report the complete sequence of the chloroplast genome of $P$. argentatum and describe the development of DNA barcodes. The complete sequence of the $P$. argentatum chloroplast genome has enabled us to construct chloroplast transformation vectors based on the exact sequence of the large inverted regions, and to identify novel insertion sites in non-essential, non-coding regions. Barcode analysis with the matK gene and $p s b \mathrm{~A}$ trn $\mathrm{H}$ spacer sequence allowed us to discriminate three of four Parthenium species from each other and from $P$. argentatum, and a subset of the $P$. argentatum lines from each other. These barcodes will be used in our breeding program. 


\section{Results}

Genome size and gene content, order and organization The complete nucleotide sequence of the chloroplast genome of Parthenium argentatum is represented in a circular map (Figure 1; Genbank Accession GU120098). It is $152,803 \mathrm{bp}$ in size and includes a duplicated region of inverted repeats (IR) of 24,424 bp. The IR are separated by small single copy (SSC) and large single copy (LSC) regions of $19,390 \mathrm{bp}$ and $84,565 \mathrm{bp}$, respectively. The total $\mathrm{G}+\mathrm{C}$ content of the whole chloroplast genome is $37.6 \%$. The gene content and arrangement were observed to be similar to those in Lactuca sativa and Helianthus annuus [22], and Guitozia abyssinica (NC 010601), including one large (Inv1) and one small inversion (Inv2) in the LSC region. There are 85 genes coding for proteins (Additional file 1), including six that are duplicated in the IR regions. There are four rRNA genes that are also duplicated in the IR regions. In total there are 43 tRNA genes, seven of which are duplicated in the IR, one in the SSC, with the remaining 28 scattered in the LSC region.

The size of the $P$. argentatum chloroplast sequence is larger than those of the three other Asteraceae chloroplast genomes (Table 1). It is close to the same size as the $L$. sativa genome, and $1.04 \mathrm{~kb}$ and $1.7 \mathrm{~kb}$ larger than the $G$. abyssinica and $H$. annuus genome, respectively, with the length differences primarily found in the LSC and SSC domains. The sequence differences between $P$. argentatum and each of the other three chloroplast genomes are concentrated in the noncoding regions of Inv2, and the SSC and LSC regions (Figure 2). The IR regions in $P$. argentatum are shorter than those of the three other species by 210-610 bp (Table 1, Figure 2).

Based on sequence comparison of the chloroplast genome of $P$. argentatum with $H$. annuus and L. sativa, two inver-

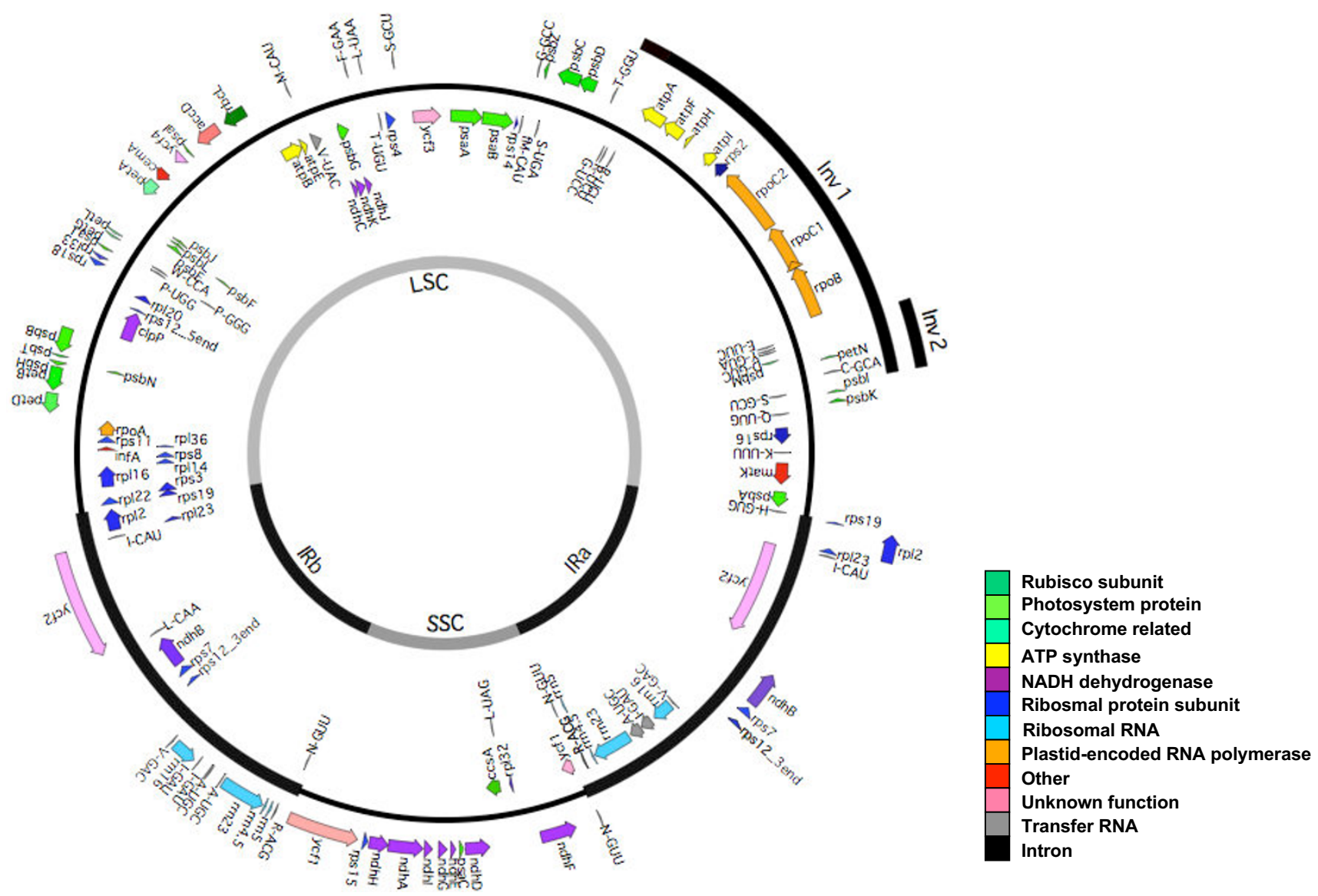

Figure I

Representative map of the chloroplast genome of Parthenium argentatum (Genbank Accession GUI20098). IR, inverted repeat; LSC, large single copy region; SSC, small single copy region; InvI, inverted sequence I; Inv2, inverted sequence 2. Gene names and positions are listed in Additional file I. 

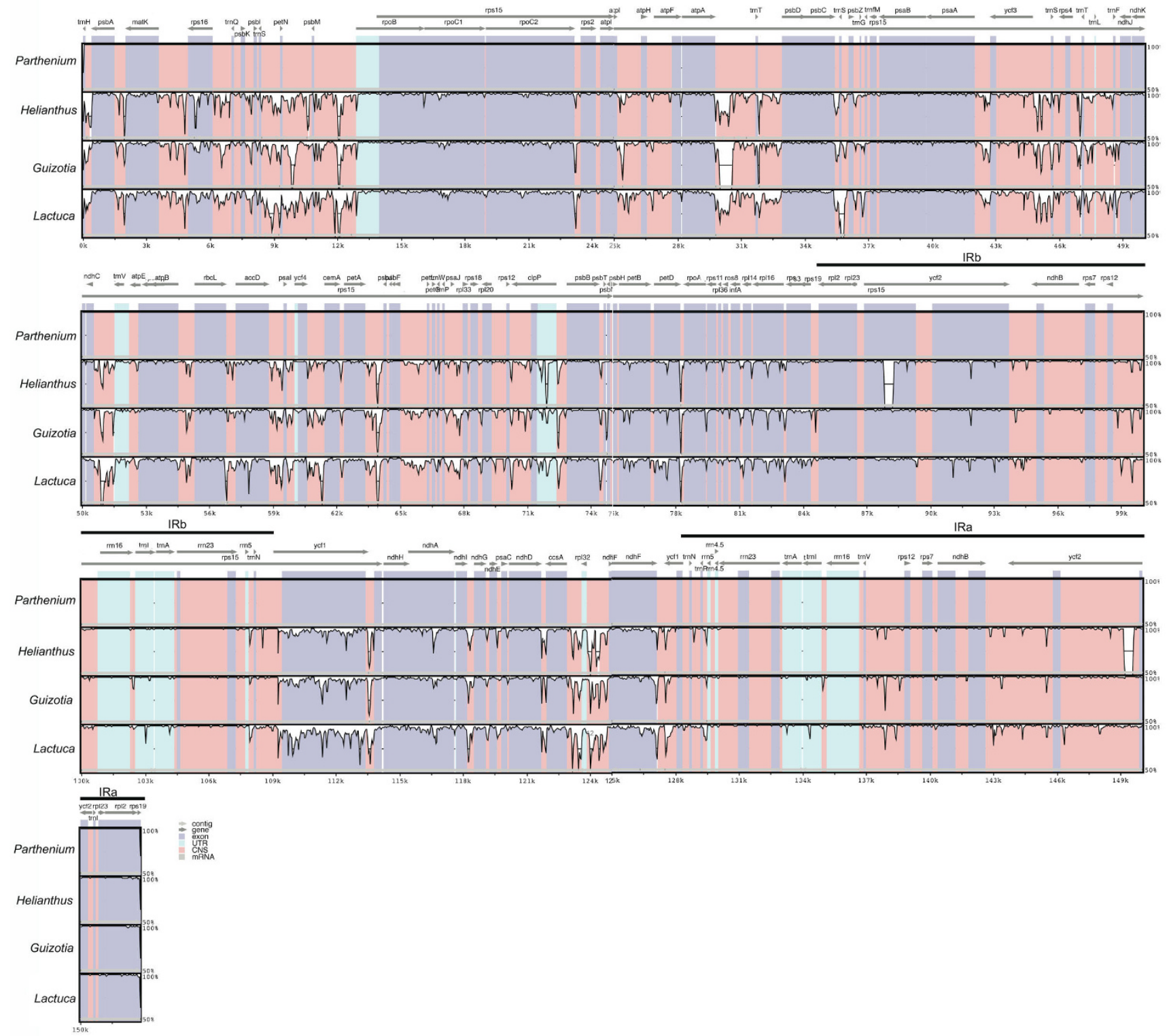

\section{Figure 2}

Chloroplast genomes of Parthenium argentatum, Helianthus annuus, Guizotia abyssinica and Lactuca sativa compared with mVISTA. A cut-off of $70 \%$ identity was used for the plot and the $Y$-scale represents the percent identity ranging from 50 to $100 \%$. Blue represents exons, green-blue represents untranslated regions, and pink represents conserved non-coding sequences (CNS). Horizontal black lines indicate the position of InvI, Inv2, IRa and IRb; SSC is flanked by IRa and IRb; grey arrows the direction of transcription.

sions of $22,890 \mathrm{bp}$ and 3,364 bp were observed in $P$. argentatum, similar to those described by Kim et al. [14] and Timme et al. [22]. In P. argentatum, one end point of the $23 \mathrm{~kb}$ inversion was located between the trnS-GCU and trnG-UCC genes. The other end point is located between the trnE-UUC and trnT-GGU genes. The second $3.4 \mathrm{~kb}$ inversion was observed within the $23 \mathrm{~kb}$ inversion, which shares one end point just upstream of the trnEUUC gene with the large inversion. The other end point of the $3.4 \mathrm{~kb}$ inversion is located between the trnC-GCA and $r p o$ B genes (Figure 1).

\section{Variation in chloroplast coding sequences of Asteraceae family members}

Variation between coding sequences of $P$. argentatum and H. annuus, G. abyssinica or L. sativa was analyzed by comparing each individual gene (Additional file 1 ) as well as the overall sequences (Figure 2 ). In general, $P$. argentatum 
Table I: Size comparison of Parthenium argentatum chloroplast genomic regions with those in other members of Asteraceae.

\begin{tabular}{lcccc}
\hline & & \multicolumn{3}{c}{ Length (bp) } \\
\cline { 2 - 5 } Plant species & Total genome & \multirow{2}{*}{ LSCa } & \multirow{2}{*}{ SSC } & IR \\
\hline Helianthus annuus & 151104 & 83530 & 18308 & 24633 \\
Guizotia abyssinica & 151762 & 18228 & 24950 & 18599 \\
Lactuca sativa & 152772 & 83636 & 25034 \\
Parthenium argentatum & 152803 & 84335 & 19390 & 24424 \\
\hline
\end{tabular}

aRegions in chloroplast genome; LSC, Large Single Copy; SSC, Small Single Copy; IR, Inverted Repeats.

coding sequences are more similar to those in G. abyssinica (98.5\% identical on average) and $H$. annuus (98.4\%), than in L. sativa $(97.2 \%)$. The greater average identity in $G$. abyssinica than in $H$. annuus is in large part due to deletions in the two copies of the $y c f 2$ loci in H. annuus, otherwise, $H$. annuus is more similar overall than G. abyssinica. Fourteen genes in H. annuus and G. abyssinica were 100\% identical to those in $P$. argentatum, compared to only four genes in L. sativa (Additional file 1). The most-divergent coding regions in the three genomes were $\gamma c f 1, a c c \mathrm{D}, c l p \mathrm{P}$, rps16, and ndhA (Figure 2).

\section{DNA barcode analysis of Parthenium}

To differentiate Parthenium taxa, a molecular approach was used in which we analyzed four different chloroplast DNA regions, which were shown to be useful DNA barcodes in past studies $[16,18,23,24]$. These regions were the $t r n \mathrm{~L}-\mathrm{UAA}$ intron, $r p o \mathrm{C}, m a t \mathrm{~K}$ and the non-coding spacer region between the two genes psbA-trn $\mathrm{H}$. Tests were conducted on DNA of three Parthenium species ( $P$. incanum, $P$. tomentosum, and $P$. schottii) and three cultivated lines of $P$. argentatum (AZ2, AZ3 and Cal6) (data not shown). The best differentiation of Parthenium species and lines within $P$. argentatum was obtained with the $p s b \mathrm{~A}$ $t r n \mathrm{H}$ spacer region barcode. There were 5 indel sites in 400 bp of DNA in the six lines tested. When $1000 \mathrm{bp}$ of the matK DNA barcode were analyzed, a total of 12 indel sites were found. In $600 \mathrm{bp}$ from the trnL-UAA intron region, only one indel site was observed. Obtaining good sequence from the $r p o \mathrm{C}$ spacer region was difficult, but in $500 \mathrm{bp}$, four indel sites were identified. Therefore, due to the higher number of informative sites, the mat $\mathrm{K}$ and psbA-trnH DNA barcodes were used for further studies of Parthenium taxa.

\section{The matK DNA barcode}

After re-evaluation of the $1000 \mathrm{bp}$ sequence of matK, an efficient barcode for Parthenium species was defined. Using the Parth-matK-F and Parth-matK-R primers, matK DNA sequences were examined in Parthenium species, lines of $P$. argentatum and AZ101, a hybrid of $P$. argentatum cv. $11591 \times$ P. tomentosum. We sampled 601 nucleotides in the matK gene, which yielded fourteen potentially informative, variable positions (2.3\%), with eight nucleotide substitutions (1.3\%) and six length mutations (indels) (1.0\%). Although the $p s b \mathrm{~A}-\mathrm{trn} \mathrm{H}$ spacer region in $P$. integrifolium DNA did amplify with the $p s b A$ trn $\mathrm{H}$ barcode primers, the mat $\mathrm{K}$ locus did not amplify with the matK-barcode primers. This matK barcode was effective at differentiating P. schottii, P. hysterophorus, and $P$. tomentosum from each other and from a group that included $P$. incanum, $P$. argentatum lines and one hybrid (Figure 3). This barcode did not differentiate $P$. incanum from the seven $P$. argentatum lines and the hybrid (Table 2).

\section{The psbA-trnH DNA barcode}

The non-coding spacer region between $p s b \mathrm{~A}$ and $\operatorname{trn} \mathrm{H}$ was used to differentiate several Parthenium species, lines of $P$. argentatum and a hybrid of two Parthenium species (Table 2). A 469 bp region was amplified via PCR using the psbA$\mathrm{F}$ and $t r n \mathrm{H}-\mathrm{R}$ primers. This region produced the best differentiation (Figure 4). We sampled 456 nucleotides in the $p s b \mathrm{~A}$ and $t r n \mathrm{H}$ spacer, which yielded fourteen potentially informative, variable positions (3.1\%), with eleven nucleotide substitutions $(2.4 \%)$ and three length mutations $(0.7 \%)$. First of all, we found that there was $100 \%$ consensus in the barcode sequence among samples tested of line AZ1 $(n=21), A Z 4(n=15)$, Cal6 $(n=17), A Z 101$ $(\mathrm{n}=3), P$. incanum $(\mathrm{n}=6)$ and $P$. tomentosum $(\mathrm{n}=5)$. On the other hand, there was a second barcode sequence within line AZ2 (minority barcode in $6.5 \%$ of total, $\mathrm{n}=$ 31), AZ3 (minority barcode $6.7 \%, \mathrm{n}=15$ ), AZ5 (minority barcode 20\%, $\mathrm{n}=15$ ), AZ6 (minority barcode $15 \%, \mathrm{n}=$ 20) and 11591 (50\% alternative barcode, $n=20)$. The minority or alternative barcodes differed from the corresponding common barcode by one to three bases.

The psbA-trn $\mathrm{H}$ spacer barcode differentiated P. hysterophorus, $P$. integrifolium and $P$. schottii from each other and from all the other species and lines. The psbA-trn $\mathrm{H}$ spacer barcode of $P$. argentatum cultivar 11591 and the two breeding lines C156 and C86 was different from those of the remaining $P$. argentatum lines, $P$. tomentosum and $P$. incanum. The barcode of AZ101, which is a hybrid between $P$. argentatum cultivar (cv.) 11591 and P. tomen- 


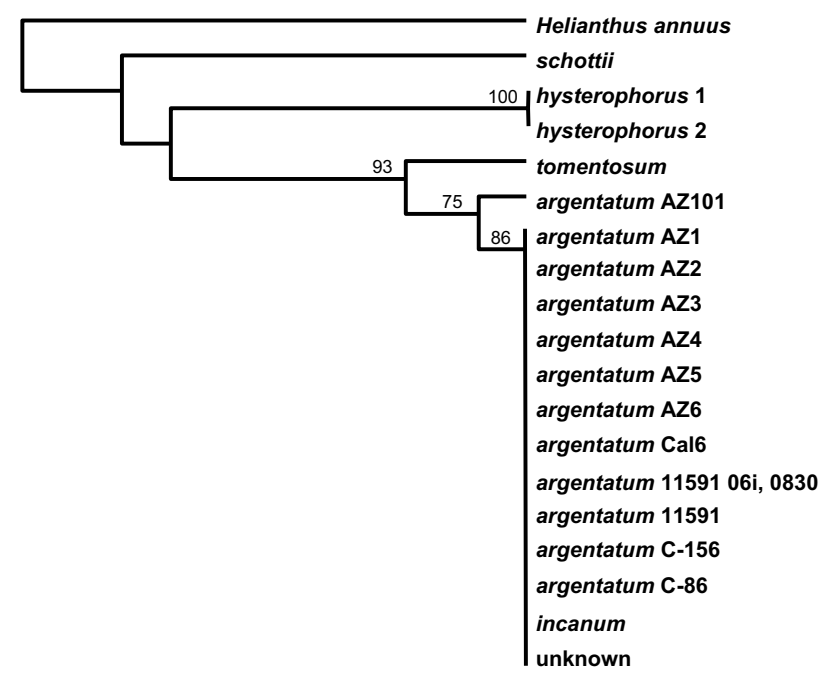

Figure 3

Differentiation by matK barcode (Genbank Accession 1230803) in Parthenium species. UPGMA in Jukes-Cantor mode, with gamma correction, was used to construct the tree, with statistical support for tree branches evaluated by bootstrap analysis ( 1000 replicates), indicated above the node. Helianthus annuus is included as an outgroup.

tosum, is similar to or identical to that of $P$. tomentosum. Parthenium incanum's barcode clustered with two AZ2 variants and a plant of unknown parentage, indicating their close relationship. Analysis with both the $p s b \mathrm{~A}-t r n \mathrm{H}$ spacer and matK barcodes provided further differentiation (Figure 5). The combined barcodes of AZ101 and $P$. tomentosum are more similar to each other than to all those of the $P$. argentatum lines together with $P$. incanum. Drilling deeper, the barcodes of cv. 11591/C156/C86 are different from those of $P$. incanum and all the remaining $P$. argentatum lines.

\section{Discussion}

Comparative genome organization and structure

Asteraceae is one of the largest families of flowering plants with approximately 1,500 genera and 23,000 species. Production of secondary metabolites is a key feature of this diverse family. For example, several genera within the Asteraceae produce high molecular weight rubber in the cytosol, including Lactuca sativa [25] and Taraxacum koksaghyz [26], and the species of interest to our studies, Parthenium argentatum. To support efforts to improve the levels of rubber production in this industrial crop, the sequence of the chloroplast genome of $P$. argentatum was determined. This information is useful for our efforts in chloroplast engineering. The barcodes we present will be used in breeding of commercially important lines in the genus Parthenium.
Within the Asteraceae, the $P$. argentatum chloroplast sequence represents the fourth complete sequence. This sequence reveals that the chloroplast genomes of $P$. argentatum, H. annuus, G. abyssinica and L. sativa are identical in gene order and content (Figure 1; Figure 2). The four genomes differ slightly in length, with the chloroplast genome in $P$. argentatum somewhat longer than those in L. sativa, G. abyssinica and $H$. annuus, respectively (Table 1). Two inversions in the chloroplast genome are shared by two of the three subfamilies of the Asteraceae [14,22] and are present in $P$. argentatum (Figure 1 ). In $H$. annuus, the IR-located gene $y c f 2$ has an internal deletion of $455 \mathrm{bp}$ that is not found in the three other genomes. The large chloroplast gene $\gamma c f 2$ specifies an expressed protein [27], whose function has not yet been determined, although $y c f 2$ 's homology to ATPases was noted by Wolfe [28]. Our protein domain analysis [29] suggests similarity with conserved domains of the ATPase AAA family that perform chaperone-like functions involved in assembly or disassembly of protein complexes. In some chloroplast genomes, particularly in grasses, $y c f 2$ is entirely absent [30]. Despite that fact, knockout studies in Nicotiana tabacum demonstrated that $\gamma c f 2$ is essential for survival [31]. There must be sufficient coding sequence remaining in $H$. annuus to provide any essential $y c f 2$ function. Interestingly, $y c f 2$ is one of the eight fastest evolving genes in the chloroplast genome (Additional file $1 ;$ [32]). Notably, this rapid evolution has taken place in the framework of the more slowly evolving IR region as a whole (Figure 2; [33]). Another notable size difference in coding regions is found in the SSC region. The SSC region of the chloroplast genome of $P$. argentatum is 791 to 1162 bp longer than that in the other species (Table 1 ). Within the SSC region, the $y c f 1$ gene has a 3'-deletion in H. annuus, G. abyssinica and L. sativa (Figure 2). Similar to $\gamma c f 2, \gamma c f 1$ encodes a protein of unknown function that is also essential [31]. It appears to be a multi-pass transmembrane protein, with no clear association to known functional domains.

In a comparative study of individual genes of $P$. argentatum, H. annuus, G. abyssinica and L. sativa, we identified several sequences with high levels of differences along their length, the most divergent including the already mentioned $\gamma c f 1$, and $c l p \mathrm{P}, r p s 16, \operatorname{acc} \mathrm{D}$, and $n d h \mathrm{~A}$ (Additional file 1). Interestingly, three of these genes, $\gamma c f 1$, acc $\mathrm{D}$ and $c l p \mathrm{P}$, are essential plastid genes in some taxa, but not others [31,34-37]. The presence of non-coding intronic sequences in both $n d h \mathrm{~A}$ and $r p s 16$ contributes to the divergence in those two loci $[38,39]$. These divergent sequences among the four Asteraceae chloroplast genomes identify the fastest evolving regions containing coding sequences.

Metabolic engineering of plants by inserting transgenes in the chloroplast would potentially be made more efficient with knowledge of chloroplast sequences, based on the 
Table 2: Population information for analyses of Parthenium species using DNA barcode sequences.

\begin{tabular}{|c|c|c|c|c|}
\hline \multirow[b]{2}{*}{ Parthenium species line/cultivar/hybrid } & \multirow[b]{2}{*}{ Seed Harvest year } & \multirow[b]{2}{*}{ Location } & \multicolumn{2}{|c|}{ Number of plants tested } \\
\hline & & & mat $\mathrm{K}$ & psbA-trnH \\
\hline \multicolumn{5}{|l|}{ argentatum } \\
\hline AZI & 2005 & $M A C^{b}$ & 5 & 21 \\
\hline AZ2 & 2005 & MAC & 5 & 15 \\
\hline$A Z 2$ & 2006 & Higby, AZ & 5 & 16 \\
\hline AZ3 & 2006 & Rush, AZ & 5 & 15 \\
\hline AZ4 & 2004 & MAC & 5 & 15 \\
\hline AZ5 & 2006 & Rush, AZ & 5 & 15 \\
\hline AZ6 & 2005 & MAC & 5 & 20 \\
\hline Cal6 & 2007 & Crit Farm & 5 & 17 \\
\hline $\mathrm{CI} 56$ & 2008 & MAC & 1 & 1 \\
\hline $\mathrm{C} 86$ & 2008 & MAC & I & 1 \\
\hline cv. $1159 \mid$ & $1989,2005,2006$ & MAC, NALPGRUc & 13 & 20 \\
\hline AZIOIa & 2002 & USALARCd, NALPGRU & 3 & 3 \\
\hline hysterophorous & 2008 & MAC & 2 & 2 \\
\hline incanum & 2007 & USALARC, WRRC & 6 & 6 \\
\hline integrifolium & 2008 & USALARC & - & 2 \\
\hline schotti & 2007 & WRRC & I & 1 \\
\hline tomentosum & 2007 & USALARC, WRRCe & 5 & 5 \\
\hline Unknown & 2008 & USALARC & I & 1 \\
\hline
\end{tabular}

ahybrid, P. argentatum II59I $\times$ P. tomentosum

bMAC, Maricopa Agricultural Center Field, University of Arizona, Maricopa, AZ

cUSALARC, US Arid Land Agriculture Research Center Greenhouse, Maricopa, AZ

dNALPGRU, National Arid Land Plant Genetic Resources Unit, Parlier, CA

eWRRC, Western Regional Research Center Greenhouse, Albany, CA

conclusions of one group that chloroplast transformation efficiency was significantly enhanced when vectors were constructed with 100\% homologous sequences [40]. Other groups have shown that precise homology may not be essential, as tobacco sequences [41] were sufficient to allow recombination in tomato [42], potato [43], and petunia [44]. The chloroplast genome sequence of $P$. argentatum was used to design a $100 \%$ specific chloroplast transformation vector (unpublished data), to maximize the possibility of successful recombination. Improving crop plants via chloroplast transformation is a viable strategy $[1,5]$ that will be pursued in this industrial crop.

\section{DNA barcodes}

Chloroplast genomic sequences were used to develop DNA barcodes to discriminate at the species level and below. The matK barcode contained sufficient information to differentiate three Parthenium species (tomentosum, hysterophorus and schottii) from each other and from $P$. argentatum and $P$. incanum. However, the matK-barcode did not differentiate $P$. incanum from $P$. argentatum or $P$. agentatum lines from each other (Figure 3 ). The psbA-trn $\mathrm{H}$ spacer barcode provided additional differentiation at the species level and below (Figure 4, 5). Interestingly, when the matK gene and the psbA-trn $\mathrm{H}$ spacer barcode information was combined, $P$. tomentosum and cv. 11591 were differentiated from the remaining $P$. argentatum lines and $P$. incanum. Using the combined barcodes, we observed that they were more similar in $P$. argentatum AZ1 to AZ6 and Cal6 lines overall than they were in the P. argentatum $\mathrm{cv}$. 11591, breeding lines C-156 and C86, and hybrid line AZ101 (Figure 5). To understand the pattern of differentiation, it would be useful to have precise information about the pedigrees of all the lines. Unfortunately, in most cases that is either lacking or incomplete. We know that AZ4 and AZ5 were selected from the same seed lot [45] and their combined barcodes are very similar (Figure 5). We cannot trace the ancestors of AZ4, AZ5 and AZ6 to understand the history of their relatedness to AZ1, AZ2, AZ3 and Cal6. The barcodes of the two P. argentatum lines $A Z 2$ and $A Z 3$ were not different, which is not surprising as AZ2 and AZ3 were selections from the same 11591 seed lot [45], however, it would be expected that their majority barcodes would be more similar to 11591 than they are. The $p s b A-t r n H$ DNA barcode analysis demonstrated that two plants of AZ2, \#8 grown in a field at Higby and \#16 grown in a field at the Maricopa Agriculture Center (MAC) have a different psbA-trn $\mathrm{H}$ barcode than the common DNA barcode sequence of AZ2 (Figure 4). These do not appear to be pure AZ2 derivatives and may represent seed contaminants. Several of the $P$. argentatum lines were homogeneous according to the psbA-trn $\mathrm{H}$ spacer sequence, including $\mathrm{AZ1}, \mathrm{AZ4}$, and $\mathrm{Cal} 6$. Other lines were less homogeneous, including AZ2, AZ3, AZ5, and AZ6, 


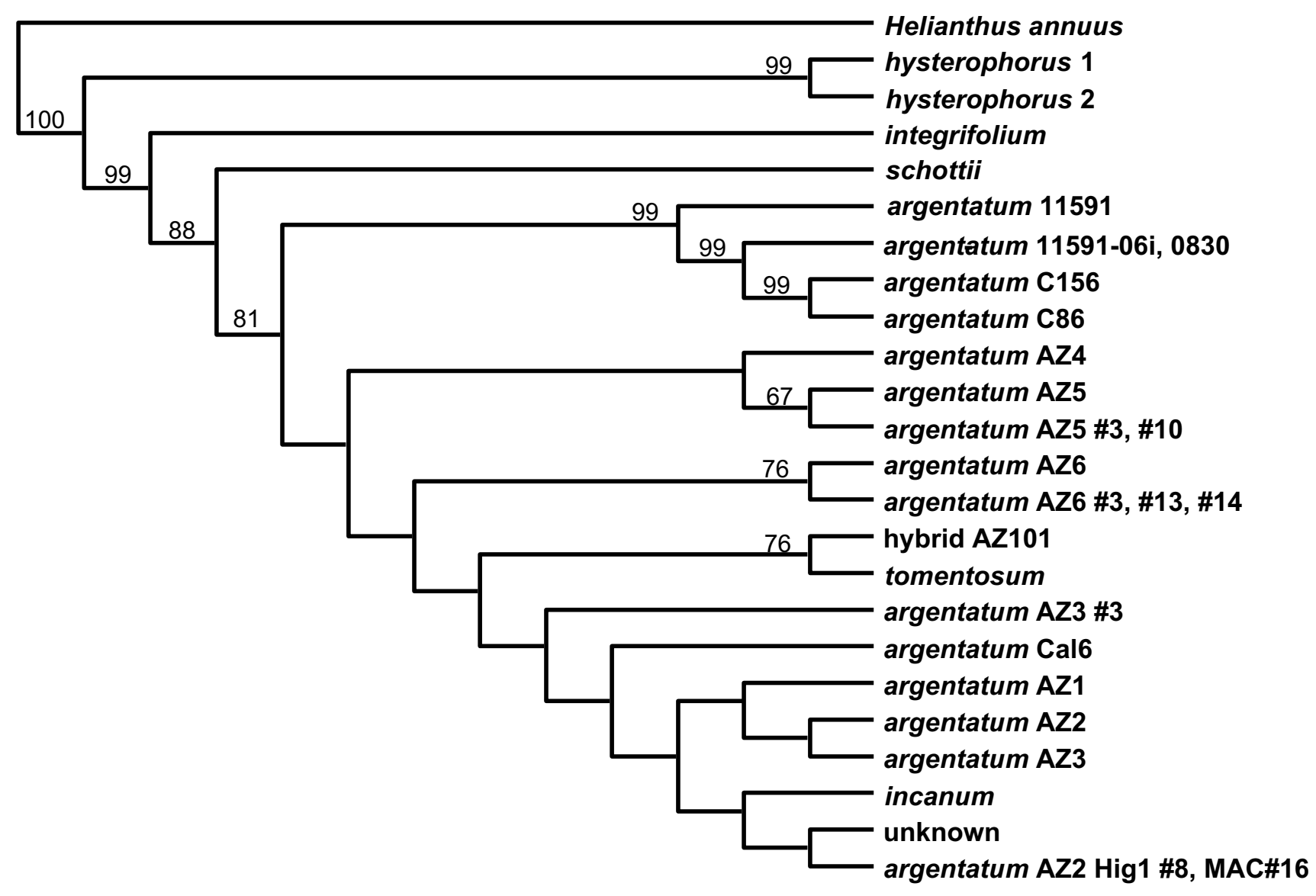

Figure 4

Differentiation by psbA-trnH spacer region barcode (Genbank Accession 1230807). This barcode was analyzed in Parthenium species, $P$. incanum, $P$. tomentosum, $P$. schottii, $P$. integrifolium, hybrid AZIOI (P. argentatum $\times P$. tomentosum) and $P$. argentatum lines AZI, AZ2, AZ3, AZ4, AZ5, AZ6, Cal6, CI56, C86 and cv. II 59I. UPGMA in Jukes-Cantor mode was used to construct the tree, with statistical support for tree branches evaluated by bootstrap analysis ( 1000 replicates), indicated above the node. Minority barcodes are indicated by \#'s after the name of the line. Helianthus annuus is included as an outgroup.

with a minority sequence present in 6 to $20 \%$ of the individuals tested. From our own observations in the field, $P$. argentatum accessions are highly heterogeneous in growth habit, suggesting that seed lots are composed of highly mixed genetic populations. This would not be unexpected for open-pollinated, self-incompatible, field-grown lines. Our barcode data support the heterogeneity and provides information that will be used immediately to differentiate breeding populations.

Classical breeding efforts will be enhanced by using the informative chloroplast DNA barcode we describe herein. We assessed the genetic purity of a small population of $P$. argentatum using the psbA-trn $\mathrm{H}$ barcode and were able to show, as described above, which lines had undergone homogenization and which had not (Figure 5). Knowledge of the purity of lines and the presence of contaminat- ing seeds, will further our breeding efforts of lines that are being advanced for latex production.

Our barcode study was useful in providing support for the maternal parent of the hybrid plant, AZ101. AZ101 is a vigorous interspecific hybrid, low in rubber concentration, but high in biomass production [46]. The line is the result of an open-pollinated cross between $P$. argentatum cv. 11591 and P. tomentosum cv. stramonium [45]. AZ101 most likely inherited its chloroplast genome from $P$. tomentosum, as AZ101 and P. tomentosum are not differentiated by the combined barcode system (Figure 5). Although we do no know the reason for the difference, our results are not the same as those from the non-DNA analyses by Ray and co-workers [47]. More extensive analysis of differences at the DNA level is necessary. 


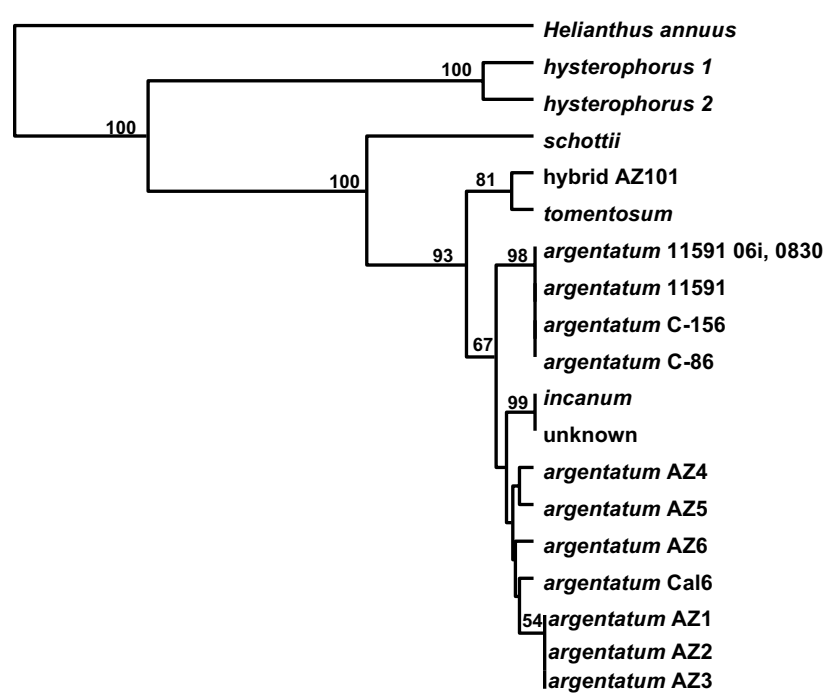

Figure 5

Barcode differentiation using the combined matK sequence and the spacer region of psbA-trnH. Combined barcodes were analyzed in Parthenium species, $P$. incanum, $P$. tomentosum, $P$. schottii, hybrid AZIOI ( $P$. argentatum $\times$ $P$. tomentosum) and $P$. argentatum lines $A Z I, A Z 2, A Z 3, A Z 4$, AZ5, AZ6, Cal6, CI56, C86 and cv. I I 59I. UPGMA in JukesCantor mode was used to construct the tree, with statistical support for tree branches evaluated by bootstrap analysis ( 1000 replicates), indicated above the node. Helianthus annuus was used as an outgroup.

According to the literature, there are about a dozen species of Parthenium growing on the North American continent. However, $P$. argentatum is the only species with commercially viable amounts of rubber. Other species such as $P$. incanum and $P$. tomentosum produce primarily resinous materials [48]. The substrate for rubber biosynthesis is isopentenyl pyrophosphate (IPP) $[49,50]$. Chloroplasts have been shown to contribute to the pool of IPP in plant cells [e.g., [51]; unpublished data, Kumar and Whalen]. If the levels of chloroplastic IPP production vary from line to line, it may be possible to breed for enhancements in substrate production by controlling the maternal parent. This suggests that hybrids could be developed using a maternal parent that produces more rubber like AZ2 combined with a higher biomass from a line like AZ101, to produce a superior plant. More experiments are necessary to understand the role of the maternal parent in rubber biosynthesis.

Our preliminary results on lack of PCR amplification from mature pollen DNA of targets within the IR regions (data not shown), suggest that chloroplasts are not present in the mature pollen and thereby are likely to be maternally inherited in $P$. argentatum. Use of plastid specific barcodes derived from the genome sequence, will allow us to definitively track any paternal inheritance in future experiments. With the recent finding of paternal inheritance in a weedy Helianthus species [52], as well as in species previously considered to lack paternal inheritance in pollen, such as Arabidopsis thaliana [8,9], it is crucial that extensive studies are performed, especially if a strategy for transgene containment depends on not transferring transgenes in pollen.

\section{Conclusion}

The genome sequence of the $P$. argentatum chloroplast will enrich the sequence resources of plastid genomes in commercial crops. The availability of the complete plastid genome sequence may facilitate improved transformation efficiency by using the precise endogenous flanking sequences and regulatory elements in chloroplast transformation vectors. The DNA barcoding study forms the foundation for genetic identification of commercially important lines of $P$. argentatum that are producing natural rubber latex for biomedical applications.

\section{Methods \\ Isolation of chloroplasts and DNA amplification, and sequencing}

A mature, greenhouse-grown Parthenium argentatum line AZ2 plant was placed in the dark for 2-days before harvesting young leaves. Chloroplasts were isolated from leaves using a 30-52\% sucrose-gradient according to both Palmer [53] and Jansen et al. [54]. Genomic DNA from chloroplasts was isolated using the GeneElute Plant Genomic Miniprep kit (Sigma-Aldrich Co.). The resulting DNA was amplified using the REPLI-g whole genome amplification kit (Qiagen, Inc.). Amplified DNA was digested with EcoRI and BstBI and examined by agarose gel electrophoresis to confirm the clear banding pattern, which indicated that the amplification product was chloroplast and not nuclear DNA.

\section{Genome sequencing, assembly and annotation}

Parthenium argentatum chloroplast genome sequencing was carried out using 454 Sequence Technology (Agencourt Biosciences, Corp). Random sequences were assembled into a draft genome sequence using Newbler as described by Chaisson et al. [55]. The whole genome was annotated using DOGMA (Dual Organellar GenoMe Annotator; [56]) to identify coding sequence, rRNAs, and tRNAs using the plastid/bacterial genetic code. To analyze the similarity of the chloroplast genes in P. argentatum and the other members of the Asteraceae, H. annuus (NC 007977), L. sativa (NC 007578), and G. abyssnica (NC 010601), the percent identity of nucleotide sequences within the open reading frame was calculated based on alignments made with ClustalW [57] and BLAST 2 SEQUENCES [58]. Inversions in the chloroplast genome of $P$. argentatum were identified by comparing the 
sequence in the inversion region [11] with that in L. sativa, H. annuus and Nicotiana tabacum (NC 001879). The end points of the inversion were determined as described by Timme et al. [22]. The mVISTA program in ShuffleLAGAN mode [59] was used to compare the DNA sequences of the chloroplast genomes of the four species of Asteraceae, using the sequence annotation information of $P$. argentatum (Figure 2 ).

\section{Identification of Parthenium species and lines}

To differentiate various Parthenium species and lines, a chloroplast DNA barcode system was developed. Four regions of the Parthenium chloroplast genome were explored, including the intron in trnL-UAA, the $r p o \mathrm{C}$ and matK genes, and the non-coding spacer between $p s b \mathrm{~A}$ trnH. Plant genomic DNA was isolated from young plants (3-4 weeks old) of available Parthenium species, cultivars, and lines using DNeasy Plant Mini Kit (Qiagen, Inc.). PCR was carried out with Phusion DNA Polymerase according to manufacturer's instructions (New England Biolabs, Inc.). The primers, TrnL-F, 5'-CGAGTTGGGGATAGAGGGACTTGAAC-3' and TrnL-R, 5'-GATATGGCGAAATAGGTAGACGCTACGGAC-3' were used to amplify trnL-UAA; for $r p o \mathrm{C}$, rpoC1-F, 5'-CATAGGAGTTGCTAAGAGTCAAATTCGG-3' and rpoC2-R, 5'-CCTTTTCTAGATCTTGATTCA CGTAGAAATTCCGC-3'; for matK, matK-F, 5'-GAATTTCAAATGGAGAATTCCAAAGC-3' and matK-end-R, 5'CGAGCTAAAGTTCTAGCACAAGAAAGTCG-3'; and for psbA-trnH， psbA-F， 5'-GGAAGTTATGCATGAACGTAATGCTC-3' and trnH-R, 5'-CGCGCATGGTGGATTCACAA TC-3'. PCR products were sequenced in both directions. Sequences were compared and any sequences with differences from the majority sequence were re-sequenced in both directions. Barcode differentiations were visualized using the UPMGA best tree method in Jukes-Cantor mode and then bootstrapped with 1000 replicates according to manufacturer's instructions in MacVector (MacVector, Inc.). Helianthus annuus was included as an outgroup.

Based on preliminary analysis of selected taxa of Parthenium, the central region of the matK gene was the best for finding divergence in Parthenium species. DNA from $P$. schottii, P. tomentosum, $P$. incanum, a cultivar of $P$. argentatum cv. 11591, nine lines of $P$. argentatum (AZ1, AZ2, AZ3, AZ4, AZ5, AZ6, C156, C58 and Cal6) and AZ101 (a hybrid of $P$. argentatum $\mathrm{CV} 11591 \times P$. tomentosum) was amplified via PCR with a $60^{\circ} \mathrm{C}$ annealing temp, using primers Parth-matK-F, 5'-CAAGCTCATCTGGAAATCTTGGTTCAGGCTC-3' and Parth-matK-R, 5'-GCCAACGATCCAACCAGAGGCATAATTGG-3'. The PCR products were sequenced in both directions using the same primers. In addition, the non-coding spacer region between the two genes psbA-trn $\mathrm{H}$ (500 bp) was used to further differentiate the Parthenium taxa. DNA was amplified with the PCR using primers psbA-F and trnH-R at an annealing temperature of $58^{\circ} \mathrm{C}$. PCR products were sequenced in both directions with the following primers, psbAF1-seq, 5'-GCTGCTATTGAAGCTCCATC-3' and Rev1-seq-trnh Gua, 5'-CCTTGATCCACTTGGCTACATCCG-3'.

\section{Abbreviations}

IR: inverted repeat; SSC: small single copy; LSC: large single copy; bp: base pair; kb: kilobase pair; INV: inverted region.

\section{Authors' contributions}

SK designed and performed all aspects of the laboratory research, isolated chloroplasts, assembled the genome sequence, compared the coding sequences in the four genomes, designed and performed all barcode amplifications and sequencing, aligned the sequences, and wrote the first draft. FMH conceived of and participated in the sequencing of the chloroplast genome. CMM facilitated all aspects of the laboratory work and revised the manuscript. KC conceived this study, provided the plant lines, and revised the manuscript. MCW supervised the work, assisted in the design of this study, with SK interpreted all data, performed analysis of barcode sequence alignments, and revised all versions of the manuscript. All authors read and approved the final manuscript.

\section{Additional material}

\section{Additional file 1}

Location of Parthenium argentatum (Genbank Accession 1230297) chloroplast genes in the genome sequence. The coordinates of genes in the chloroplast genome of Parthenium argentatum and comparison of the sequence of these genes (\% identity) with those in Helianthus annuus, Guitozia abyssinica and Lactuca sativa.

Click here for file

[http://www.biomedcentral.com/content/supplementary/14712229-9-131-S1.PDF]

\section{Acknowledgements}

Thanks to Dr. William Belknap and Mr. David Rockhold for helping with the bioinformatics tools used in this study, Drs. Terry Coffelt and Lauren Johnson for sending us seeds, and Drs. Yong Gu and Kent McCue for critical review. This work was funded by USDA-ARS project \# 5325-41000-043OOD and Yulex, Corp. via CRADA \#58-3K95-6-I 172.

\section{References}

I. Daniell H, Kumar S, Dufourmantel N: Breakthrough in chloroplast genetic engineering of agronomically important crops. Trends Biotechnol 2005, 23:238-245.

2. Maliga P: Molecular farming: plant-made pharmaceuticals and technical proteins. In Annals of Botany Volume 96. Edited by: Fischer, R, Schillberg S. Weinheim: Wiley-VCH Verlag GmbH \& Co. KgaA. Ann Bot; 2005:169-175.

3. Maliga P: Plastid transformation in higher plants. Annu Rev Plant Biol 2004, 55:289-3I3.

4. Lössl A, Eibl C, Harloff HJ, Jung C, Koop HU: Polyester synthesis in transplastomic tobacco (Nicotiana tabacum L.): significant 
contents of polyhydroxybutyrate are associated with growth reduction. Plant Cell Rep 2003, 21:891-899.

5. Bock R: Plastid biotechnology: prospects for herbicide and insect resistance, metabolic engineering and molecular farming. Curr Opin Biotechnol 2007, 18:100-106.

6. Maliga $\mathrm{P}:$ Towards plastid transformation in flowering plants. Trends Biotech 1993, I I: I0I-107.

7. Daniell H, Datta R, Varma S, Gray S, Lee SB: Containment of herbicide resistance through genetic engineering of the chloroplast genome. Nat Biotechnol 1998, 16:345-348.

8. Azhagiri AK, Maliga P: Exceptional paternal inheritance of plastids in Arabidopsis suggests that low-frequency leakage of plastids via pollen may be universal in plants. Plant $J 2007$, 52:817-823.

9. Svab Z, Maliga P: Exceptional transmission of plastids and mitochondria from the transplastomic pollen parent and its impact on transgene containment. Proc Natl Acad Sci USA 2007, 104:7003-7008.

10. Raubeson LA, Jansen RK: Chloroplast genomes of plants. In Diversity and Evolution of Plants-Genotypic and Phenotypic Variation in Higher Plants Edited by: Henry H. Wallingford: CABI Publishing; 2005:45-68.

II. Jansen RK, Palmer JD: A Chloroplast DNA Inversion Marks an Ancient Evolutionary Split in the Sunflower Family (Asteraceae). Proc Natl Acad Sci USA 1987, 84:581 8-5822.

12. Doyle JJ, Doyle JL, Ballenger JA, Palmer JD: The distribution and phylogenetic significance of a $\mathbf{5 0} \mathbf{~ k b}$ chloroplast DNA inversion in the flowering plant family Leguminosae. Mol Phylogenet Evol 1996, 5:429-438.

13. Doyle JJ, Davis JI, Soreng RJ, Garvin D, Anderson MJ: Chloroplast DNA inversions and the origin of the grass family (Poaceae). Proc Natl Acad Sci USA 1982, 89:7722-7726.

14. Kim K-J, Choi K-S, Jansen RK: Two chloroplast DNA inversions originated simultaneously during the early evolution of the sunflower family (Asteraceae). Mol Biol Evol 2005, 22: I-I0.

15. Stoeckle M: Taxonomy, DNA, and the bar code of life. Bioscience 2003, 53:796-797.

16. Taberlet P, Coissac E, Pompanon F, Gielly L, Miquel C, Valentini A, Vermat T, Corthier G, Brochmann C, Willerslev E: Power and limitations of the chloroplast trnL (UAA) intron for plant DNA barcoding. Nucleic Acids Res 2007, 35: e I4-el4.

17. Shaw J, Small RL: Addressing the "hardest puzzle in American pomology:" phylogeny of Prunus sect. Prunocerasus (Rosaceae) based on seven noncoding chloroplast DNA regions. Am J Bot 2004, $91: 985-996$.

18. Kress WJ, Wurdack KJ, Zimmer EA, Weigt LA, Janzen DH: Use of DNA barcodes to identify flowering plants. Proc Natl Acad Sci USA 2005, 102:8369-8374.

19. Shaw J, Lickey EB, Beck JT, Farmer SB, Liu W, Miller J, Siripun KC, Winder CT, Schilling ED, Small RL: The tortoise and the hare II: relative utility of $2 \mathrm{I}$ noncoding chloroplast DNA sequences for phylogenetic analysis. Am J Bot 2005, 92:142-166.

20. Chase MW, Salamin N, Wilkinson M, Dunwell JM, Kesanakurth RP, Haidar N, Savolainen V: Land plants and DNA barcodes: shortterm and long-term goals. Phil Trans $R$ Soc $B$ 2005, 360:1889-1895.

21. Chase MW, Cowan RS, Hollingsworth PM, Berg $C$ van den, Madrinan S, Petersen G, Seberg O, Jorgsensen T, Cameron KM, Carine M, Pedersen N, Hedderson TAJ, Conrad F, Salazar GA, Richardson JE, Hollingsworth ML, Barraclough TG, Kelly L, Wilkinson M: A proposal for a standardised protocol to barcode all land plants. Taxon 2007, 56:295-299.

22. Timme RE, Kuehl JV, Boore JL, Jansen RK: A comparative analysis of the Lactuca and Helianthus (Asteraceae) plastid genomes: identification of divergent regions and categorization of shared repeats. Am J Bot 2007, 94:302-312.

23. Hilu KW, Borsch T, Muller K, Soltis DE, Soltis PS: Angiosperm phylogeny based on matK sequence information. Am J Bot 2003, 90:1758-1776

24. Lahaye R, Bank M van der, Bogarin D, Warner J, Pupulin F, Gigot G, Maurin O, Duthoit S, Barraclough TG, Savolainen V: DNA barcoding the floras of biodiversity hotspots. Proc Natl Acad Sci USA 2008, 105:2923-2928.

25. Bushman BS, Scholte AA, Cornish K, Scott DJ, Brichta JL, Vederas JC, Ochoa O, Michelmore RW, Shintani DK, Knapp SJ: Identification and comparison of natural rubber from two Lactuca species. Phytochem 2006, 67:2590-2596.

26. Krotkov G: A review of literature on Taraxacum kok-saghyz Rod. Bot Rev 1945, 9:4I7-461.

27. Glick RE, Sears $B B$ : Large unidentified open reading frame in plastid DNA (ORF2280) is expressed in chloroplasts. Plant Mol Biol 1993, $21: 99-108$.

28. Wolfe $\mathrm{KH}$, Li WH, Sharp PM: Rates of nucleotide substitution vary greatly among plant mitochondrial, chloroplast, and nuclear DNAs. Proc Natl Acad Sci USA 1987, 84:9054-9058.

29. Marchler-Bauer A, Anderson JB, Derbyshire MK, DeWeese-Scott $C$, Gonzales NR, Gwadz M, Hao L, He S, Hurwitz DI, Jackson JD, Ke Z, Krylov D, Lanczycki CJ, Liebert CA, Liu C, Lu F, Lu S, Marchler GH, Mullokandov M, Song JS, Thanki N, Yamashita RA, Yin Jj, Zhang D, Bryant SH: CDD: a conserved domain database for interactive domain family analysis. Nucleic Acids Res 2007, 35:237-240.

30. Millen RS, Olmstead RG, Adams KL, Palmer JD, Lao NT, Heggie L, Kavanagh TA, Hibberd JM, Gray JC, Morden CW, Calie PJ, Jermiin LS, Wolfe $\mathrm{KH}$ : Many parallel losses of infA from chloroplast DNA during angiosperm evolution with multiple independent transfers to the nucleus. Plant Cell 200I, 13:645-658.

31. Drescher A, Ruf S, Calsa TJ, Carrer H, Bock R: The two largest chloroplast genome-encoded open reading frames of higher plants are essential genes. Plant J 2000, 22:97-I04.

32. Kim KJ, Lee HL: Complete Chloroplast Genome Sequences from Korean Ginseng (Panax schinseng Nees) and Comparative Analysis of Sequence Evolution among 17 Vascular Plants. DNA Res 2004, I I:247-26I.

33. Rainer MM, Neckermann K, Igloi GL, Kossel H: Complete Sequence of the Maize Chloroplast Genome: Gene Content, Hotspots of Divergence and Fine Tuning of Genetic Information by Transcript Editing. J Mol Biol 1995, 25 I:6।4-628.

34. Wakasugi T, Tsudzuki T, Sugiura M: The genomics of land plant chloroplasts: Gene content and alternation of genomic information by RNA editing. Photosynth Res 2001, 70:107-1 I8.

35. Kode V, Mudd EA, lamtham S, Day A: The tobacco plastid accD gene is essential and is required for leaf development. Plant J 2005, 44:237-244.

36. Shikanai T, Endo T, Hashimoto T, Yamada $Y$, Asada K, Yokota A: Directed disruption of the tobacco ndhB gene impairs cyclic electron flow around photosystem I. Plant Cell Physiol 200I, 42:264-273.

37. Kuroda $\mathrm{H}$, Maliga $\mathrm{P}$ : The plastid clpPI gene is essential for plant development. Nature 2003, 425:86-89.

38. Small RL, Ryburn JA, Cronn RC, Seelanan T, Wendel JF: The tortoise and the hare: choosing between noncoding plastome and nuclear Adh sequences for phylogenetic reconstruction in a recently diverged plant group. Am J Bot $|998,85:| 30|-| 3 \mid 5$.

39. Baker WJ, Hedderson TA, Dransfield J: Molecular phylogenetics of subfamily Calamoideae (Palmae) based on nrDNA ITS and cpDNA rps 16 intron sequence data. Mol Phylogenet Evol 2000, 14:195-217.

40. Kumar S, Dhingra A, Daniell H: Stable transformation of the cotton plastid genome and maternal inheritance of transgenes. Plant Mol Biol 2004, 56:203-2I6.

4I. Kavanagh TA, Thanh ND, Lao NT, McGrath N, Peter SO, Horváth EM, Dix PJ, Medgyesy P: Homeologous Plastid DNA Transformation in Tobacco is Mediated by Multiple Recombination Events. Genetics 1999, 152:1111-1122.

42. Ruf S, Hermann M, Berger IJ, Carrer H, Bock R: Stable genetic transformation of tomato plastids and expression of a foreign protein in fruit. Nat Biotechnol 200I, 19:870-875.

43. Sidorov VA, Kasten D, Pang S, Hajdukiewicz PTJ, Staub JM, Nehra N: Stable chloroplast transformation in potato: Use of green fluorescent protein as a plastid marker. Plant J 1999, 19:209-216

44. Zubko MK, Zubko El, Zuilen KV, Meyer P, Day A: Stable transformation of petunia plastids. Transgenic Res 2004, I3:523-530.

45. Ray DT, Dierig DA, Thompson AE, Coffelt TA: Registration of six guayule germplasms with high yielding ability. Crop Sci 1999 , 39:300

46. Veatch ME, Ray DT, Mau CJD, Cornish K: Growth, rubber, and resin evaluation of two-year-old transgenic guayule. Ind Crop Prod 2005, 22:65-74.

47. Ray DT, Coffelt TA, Dierig DA: Breeding guayule for commercial production. Ind Crop Prod 2005, 22:15-25. 
48. Chow P, Nakayama FS, Youngquist JA, Muehl JH, Krzysik AM: Durability of wood/plastic composites made from Parthenium species. In Thirty-third annual meeting of the International Research Group on Wood Preservation, Section 4, Processes and Properties Cardiff, Wales. Stockholm, Sweden: IRG Secretariat; 2002:I2-I7.

49. Archer BL, Audley BG, Cockbain EG, McSweeney GP: The biosynthesis of rubber. Biochem J 1963, 89:565-574.

50. Cornish K, Backhaus RA: Rubber transferase activity in rubber particles of guayule. Phytochem 1990, 29:3809-38।3.

51. Dudareva N, Andersson S, Orlova I, Gatto N, Reichelt M, Rhodes D, Boland W, Gershenzon J: The nonmevalonate pathway supports both monoterpene and sesquiterpene formation in snapdragon flowers. Proc Natl Acad Sci 2005, I 02:933-938.

52. Ellis JR, Bentley KE, McCauley DE: Detection of rare paternal chloroplast inheritance in controlled crosses of the endangered sunflower Helianthus verticillatus. Heredity 2008, I 00:574-580.

53. Palmer JD: Isolation and structural analysis of chloroplast DNA. Methods Enzymol 1986, I I 8:167-I86.

54. Jansen RK, Raubeson LA, Boore JL, DePamphilis CW, Chumley TW, Haberle RC, Wyman SK, Alverson AJ, Peery R, Herman SJ, Fourcade HM, Kuehl JV, McNeal JR, Leebens-Mack J, Cui L: Methods for obtaining and analyzing whole chloroplast genome sequences. Methods Enzymol 2005, 395:348-384.

55. Chaisson MJ, Pevzner PA: Short read fragment assembly of bacterial genomes. Genome Res 2008, I 8:324-330.

56. Wyman SK, Jansen RK, Boore JL: Automatic annotation of organellar genomes with DOGMA. Bioinformatics 2004, 20:3252-3255.

57. Thompson JD, Higgins DG, Gibson TJ: CLUSTAL W: improving the sensitivity of progressive multiple sequence alignment through sequence weighting, position-specific gap penalties and weight matrix choice. Nucleic Acids Res 1994, 22:4673-4680.

58. Tatiana AT, Madden TL: Blast 2 sequences - a new tool for comparing protein and nucleotide sequences. FEMS Microbiol Lett 1999, I 74:247-250.

59. Frazer KA, Pachter L, Poliakov A, Rubin EM, Dubchak I: VISTA: computational tools for comparative genomics. Nucleic Acids Res 2004, 32:273-279.

Publish with Bio Med Central and every scientist can read your work free of charge

"BioMed Central will be the most significant development for disseminating the results of biomedical research in our lifetime. "

Sir Paul Nurse, Cancer Research UK

Your research papers will be:

- available free of charge to the entire biomedical community

- peer reviewed and published immediately upon acceptance

- cited in PubMed and archived on PubMed Central

- yours - you keep the copyright
BioMedcentral 